\section{INFLUENCE OF SHAPE OF} PRESSURE VESSEL SHELL ON BOLT WORKING LOAD AND TIGHTNESS

JIRI ZACAL, JAN PAVLIK, IVANA KUNZOVA

VSB-Technical University of Ostrava, Faculty of Mechanical Engineering, Department of Machine Parts and Mechanism

Ostrava, Czech Republic

DOI: 10.17973/MMSJ.2021_12_2021116

jiri.zacal@vsb.cz

The area of flange joints with gasket includes many types of pressure vessels, which are mainly defined by the purpose of use and specific load conditions. These differences in definitions caused the existence of many types of pressure vessels with different shell shapes. Calculations of basic shapes are defined by standards. However, in some fields of engineering practice, these shapes are atypical. The article discusses the issue of circular sealed flange joints with a nonstandard shape of the pressure chamber shells. The aim of this article is to describe influence of shape of pressure vessel shell on bolt working load and the final tightness of the sealed joint using FEM.

KEYWORDS

Flange Joints, Tightness, Gasket, Bolt Pretension, Pressure Vessel, Circular Flange, Shell.

\section{INTRODUCTION}

Many areas in technical practice includes a pressure vessels device, which are represent main part of function system. Furthermore, strict requirements are also often applied, especially for safety and leak rate in particular load conditions. Most critical parts of pressure vessel are sealed joints. For this purpose, a circular flange connection is usually used (see Fig. 1).

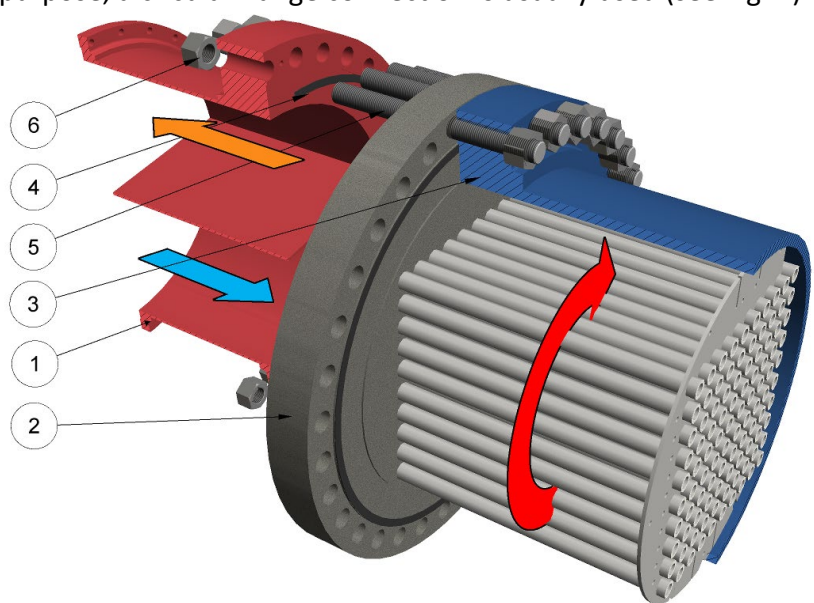

Figure 1. Example of circular flange joint with gasket [Zacal 2016] The ability to sealing depend on the gasket normal pressure. This parameter is directly bounded to the bolt pretension in assembly condition and to the bolt working load in subsequent conditions as well. Knowledge of magnitude of bolt pretension and bolt working load is crucial for design of sealed flange connection of a pressure vessel. Definition accuracy of bolt pretension highly depends on the level of knowledge of the screw frictional contacts and experiences of assembly workers. Even that, sufficient accuracy can be achieved using e.g. measurement by CSN EN ISO 16047 standard. Nevertheless, character of bolt working load depends on considerable more influencess and properties (e.g. effect of critical temperature, transient thermal influence, material properties, construction of flange joint, type of gasket, shell thickness, stiffness of parts of flange joint and last but not least the shape of pressure vessel shell.

Standardized calculations usually define only a few basic types of flange joints. For example standard [CSN EN ISO 1591-1 2015], page 17-21, defines only fourteen flange types. However, the variety of flanges in technical practice often exceeds a defined area, e.g. due to the necessary design to increase the load-bearing capacity of the joint (reinforcement) or the specific shape of the pressure vessel due to the technology of production of a particular medium.

This article discusses the issue of influence of shape of pressure vessel shell on bolt working load and tightness of the joint.

The first part provides the analysis results for symmetrical shape of pressure vessel shell. The next section depicts example of asymmetrical shape of pressure vessel shape. For the purpose of determination of shell shape influence, finite element method (FEM) and calculation by CSN EN 1591-1 was used. The last part of the article discusses the final results and propose calculation methodology of these nonstandard flange joints.

All calculations and generated FEM images are created by ANSYS Workbench.

\section{SYMMETRICAL SHAPE OF PRESSURE VESSEL SHELL}

For analysis was used both symmetric flanges (see Fig. 2), which are correspond to construction of Floating Type Joint (FLT). These joints are arguably the most commonly used type of flanges in engineering practice. For FLT joints are typical, that do not allow the flanges to contact metal around sealing surface. Fig. 2 shows specification of basic parameters of the analysed flange joint [Zacal 2020].

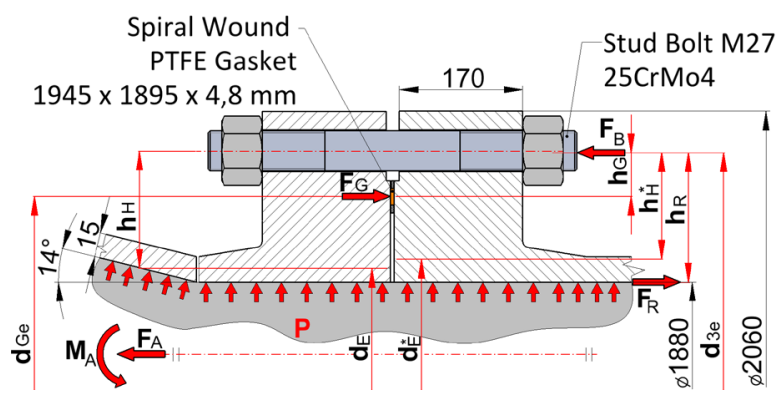

Figure 2. Specification of the flange and shell geometry [Zacal 2020] The shape of the shell, depicts in Fig. 2, corresponds to only one of a sample, which are given by standard. This standard defines several the most commonly used type of flanges and shells, see [CSN EN ISO 1591-1 2015] page 17 - 21. After analyses of the standard calculation, it is clear, that the angle of conical shell affects especially parameters related to flange flexibility and final loads limits of flanges by coefficients of correction. The character of bolt working load is in direct dependence to the flange and shell stiffness.

In some cases, in technical practise, the customer may request a special shell modification e.g. due to necessary construction changes. In one particular cause was necessary to insert new part of cylindrical shell extension between current neck of flange with conical hub and conical shell (see Fig. 3). But this new design is atypical in compare with standard shapes. However, it is not clear, how to approach the solution of such a connection. Whether to use the method of the CSN EN 1591 
standard for the solution of a cylindrical or conical shape of shell, or what differences can be expected from the point of view of tightness and bolt working load. So, in this case, using the Final Element Method (FEM) is appropriate.

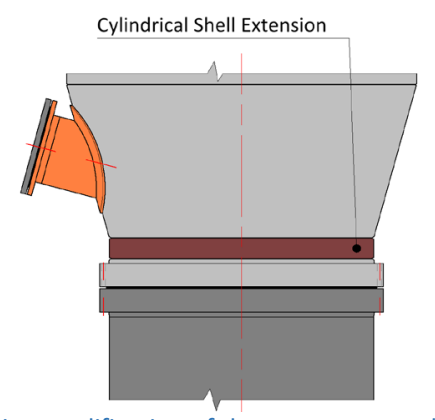

Figure 3. Design modification of the pressure vessel [Zacal 2020] For comparison purpose it is proper to analyse variant without cylindrical shell extension and simple cylindrical shape of shell too. Tab. 1 shows the loads parameters. The load conditions are designated by numbers. The first column characterizes the assembly condition, the other one depicts subsequent conditions. The parameters marked $M_{A}$ and $F_{A}$ define external loads of pressure vessel, affect from bending moment and axial force (see Fig. 2). These external additional loads (e.g. from the thermal expansion of the connected pipe) were defined according to standard [CSN EN ISO 1591-1 2015] page 17, even for FEM analysis. Depicted values in Tab. 1 was designed for purpose of analysing.

\begin{tabular}{|c|c|c|c|}
\hline Load Conditions & $\mathrm{I}=0$ & $\mathrm{I}=1$ & $\mathrm{I}=2$ \\
\hline $\mathbf{P}[\mathrm{MPa}]$ & 0 & 1.014 & 1.014 \\
\hline $\mathbf{T}\left[\mathbf{C}^{\circ}\right]$ & 22 & 22 & 200 \\
\hline $\mathbf{M}_{\mathbf{A}}[\mathrm{kNm}]$ & - & - & 143 \\
\hline $\mathbf{F}_{\mathrm{A}}[\mathrm{kN}]$ & - & - & 3.8 \\
\hline
\end{tabular}

Table 1. Table with specification of load conditions

First, the influence of pressure vessel shape of shell to bolt working load was analysed. Very often is, an opinion widely spread among laymen, that bolt working load always increases in case of pressure vessels which are loads by a positive inner pressure. However, the reality differs from this opinion. Behaviour of bolt working load in operation condition is dependent on stiffness (i.e. design) of the joint parts (flanges, gasket, shell, and the bolts) and on the nature of the deformation due to operating load (i.e. position of operating forces). In this case, the nature of deformation of pressure vessel shell is affected by own shape too. Determination of these aspects in engineering practice is either very complex or even not possible. Due to this reality the FEM was used.

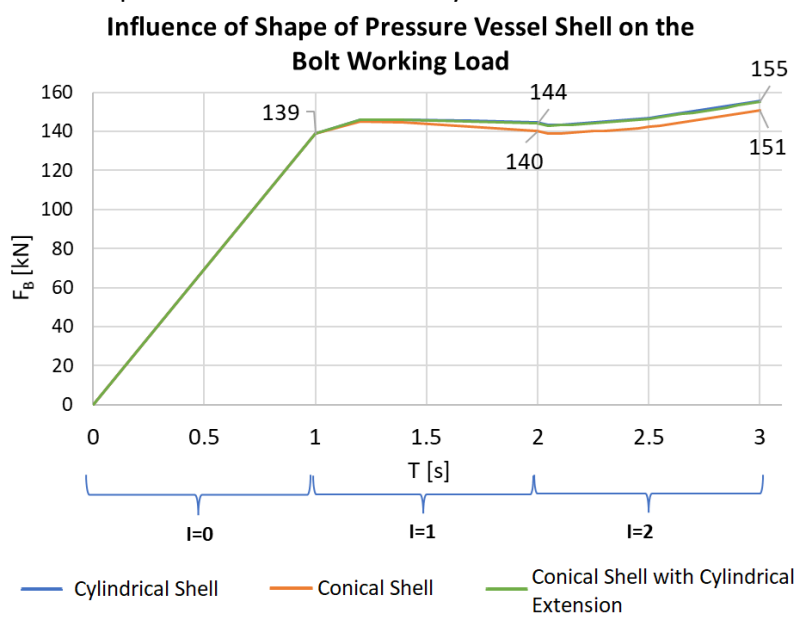

Figure 4. Influence of shape of pressure vessel shell on the bolts load

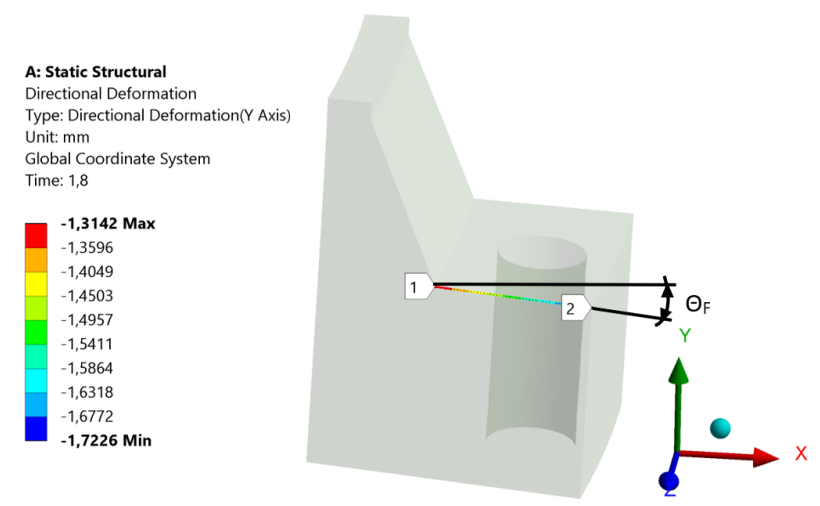

Figure 5. Angular flange inclination in FEM [Zacal 2020]

Figure 4, taken from [Zacal 2020], depicts the behaviour of bolt working load $F_{B}$ in operation conditions by FEM. Decreasing trend of bolt working load in first load condition $(I=1)$, in case of circular flange joints, is not uncommon. This behaviour is typical for floating type of joint (FLT) and metal to metal connection (MMC) with gap between flange blades [Schaaf 2003]. This decreasing trend is caused by nature of shell deformation in area of the flange hub and subsequent inclination of flanges (see Fig.5), during chamber pressurization.

\section{Influence of Shape of Pressure Vessel Shell on the}

\section{Tightness}

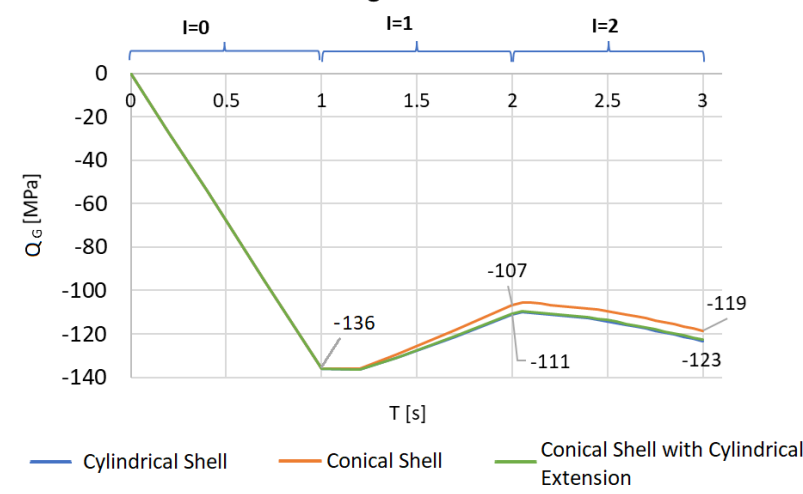

Figure 6. Influence of shape of pressure vessel shell on the tightness

Next, the influence of pressure vessel shape of shell to joint tightness was analysed. Figure 6 shows the behaviour of mean normal gasket pressure $Q_{G}$ in operating conditions by FEM. The values of normal gasket pressure in operating conditions correspond to leak rate $L=10^{-5} \mathrm{mg} /(\mathrm{s} \cdot \mathrm{m})$, which was defined by the standard [CSN EN 13555 2005]. Such a high tightness was by achieved sufficient preload in assembly conditions.

The results of behaviour of the bolt working load and joint tightness are proper to complete by inclination of flange blades (see Fig. 5). This parameter is very important from view of leak rate requirement. The FEM result of angle of flanges inclination is depicted in Fig. 7.

\section{Angular Inclination of Flanges}

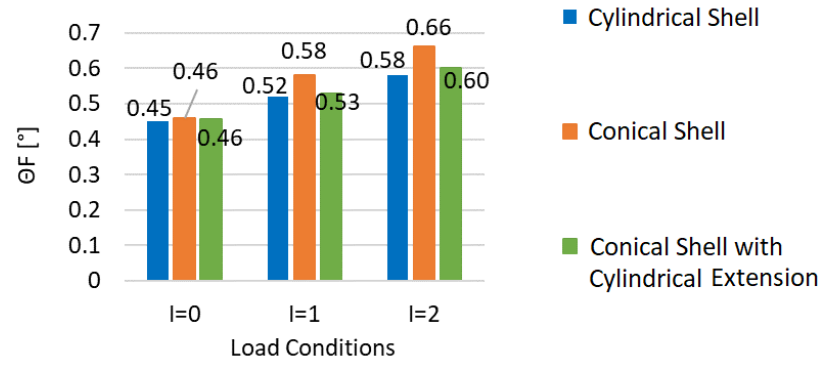

Figure 7. Results of angular inclination of flanges by FEM [Zacal 2020] 
Due to the fact, that these analysed pressure vessels were symmetrical, it was possible to use symmetry in the FEM calculation. The APDL CPCYC command (1) was used for this purpose.

cpcyc, Lab, Toler, Kcn, $d x, d y, d z$, Knonrot

Where cpcyc couples of nodes of the two side faces of cyclically symmetric model, $L a b$ is degree of freedom label for coupled nodes, Toler is tolerance of coincidence set to value 0.0001 by default, $K c n$ defines number of the coordinate system, $(d x, d y$, $d z)$ defines degree of displacement to the $K c n\left(11.739^{\circ}\right)$ and value of Knonrot was set to zero (i.e. the nodes of coupled sets are rotated into $K c$.

The FEM results were further extended by a calculation defined by standard CSN EN 1591-1. The results of the standard calculation are shown in Tab. 2 [Zacal 2020].

\begin{tabular}{|c|c|c|c|c|c|c|}
\cline { 2 - 7 } \multicolumn{1}{c|}{} & \multicolumn{2}{c|}{ Cylindrical Shell } & \multicolumn{3}{c|}{ Conical Shell } \\
\cline { 2 - 7 } \multicolumn{1}{c|}{} & $\mathbf{I}=\mathbf{0}$ & $\mathbf{I}=\mathbf{1}$ & $\mathbf{I}=\mathbf{2}$ & $\mathbf{I}=\mathbf{0}$ & $\mathbf{I}=\mathbf{1}$ & $\mathbf{I}=\mathbf{2}$ \\
\hline \multicolumn{7}{c|}{ CSN EN 1591-1 } \\
\hline$F_{B}[\mathrm{kN}]$ & 139 & 130 & 161 & 139 & 126 & 156 \\
\hline$Q_{G}[\mathrm{MPa}]$ & 131 & 93 & 118 & 135 & 91 & 116 \\
\hline$\Theta_{F}\left[^{\circ}\right]$ & 0.36 & 0.41 & 0.52 & 0.40 & 0.49 & 0.62 \\
\hline & 139 & 144 & 155 & 139 & 140 & 151 \\
\hline$F_{B}[\mathrm{kN}]$ & 136 & 111 & 123 & 136 & 107 & 119 \\
\hline$Q_{G}[\mathrm{MPa}]$ & 0.45 & 0.52 & 0.58 & 0.46 & 0.58 & 0.66 \\
\hline$\Theta_{F}\left[{ }^{\circ}\right]$ & 136 &
\end{tabular}

Table 2. Table with a comparison of analysis results

From the comparison of the results of FEM (Fig. 4, Fig. 6 and Fig. 7) and results of the standard (see Tab. 2), it is possible to see certain differences in the values of bolt working load in the state $(I=1)$. While by standard there was a decrease of bolt working load after pressurizing, the FEM results indicate a slight increase of this value. However, both the standard calculation and the FEM approach show a greater susceptibility of the conical shape of shell to causing more decrease of bolt working load under pressure from the inner medium. This decrease also affects the final load in the bolts in the state $(I=2)$. Next, the results of normal gasket pressure (see Fig. 6) and the results of the mean value of angular inclination of the flanges (see Fig. 7) nearly correspond to the values in tab. 2 , which was given by the standard. It can therefore be stated that the methodology of CSN EN 1591-1 is able to capture relatively accurately the effect of a symmetrically shaped shell connected to a flange, whether it is a cylindrical or conical connection.

The overlap curve (see Fig. 4 and Fig. 6) also confirms that a flange with an added cylindrical shell extension (see Fig. 3) can be considered as a standard connection of a cylindrical shell, without the influence of the conical shell connected above.

\section{ASYMMETRICAL SHAPE OF PRESSURE VESSEL SHELL}

Next FEM analysis was aimed to the pressure vessel with asymmetrical conical shape of shell from tube side (see Fig. 8).

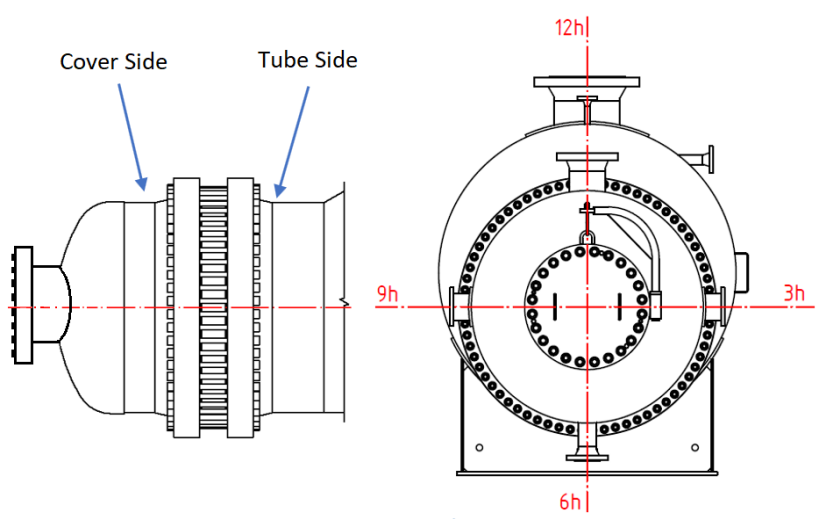

Figure 8. Asymmetrical conical shape of the pressure vessel shell In this case, the volume of symmetry simplification in the FEM was considerably limited to half.

This research was based on real situation in practice, where the circular flange joint of ethylene condenser repeatedly leaked out during the pressure test in position $3 \mathrm{~h}$ and $9 \mathrm{~h}$ (see Fig. 8).

A detailed analysis proved a negative influence of asymmetrical shape of conical shell in problematic position $9 \mathrm{~h}$ and $3 \mathrm{~h}$. The deformation character of the asymmetrical conical shell also caused an asymmetrical deformation of flange. This behaviour was watched only on the flange of tube side. Asymmetrical deformation leads to uneven sealing gasket pressure. The normal gasket pressure difference between position $12 \mathrm{~h}$ and 3h was always approximately $20 \mathrm{MPa}$, see Fig. 9 and Fig. 10 taken from [Zacal 2020]. From view of gasket tightness, it may seem that this difference is not very significant. But it is important to remember, that in some causes in technical practice, much lower sealing pressures can be defined, differences even less than $20 \mathrm{MPa}$ can be critical for tightness or required leak rate of joint. Furthermore, analysis by FEM have own limits compared to reality (e.g. geometrical accuracy of 3D model, accuracy of pretension of the bolts, some simplify operating conditions etc.).

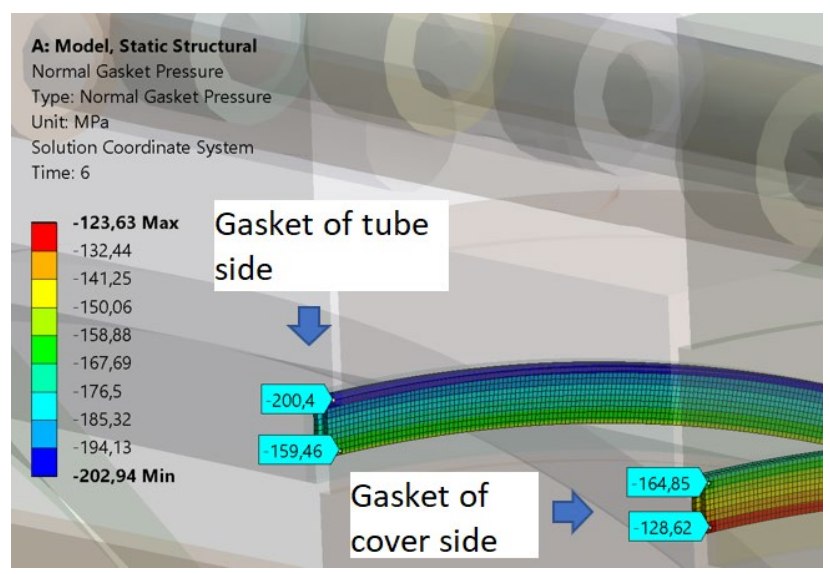

Figure 9. Normal gasket pressure in pos. $12 \mathrm{~h}$ in operating conditions

It can be simply imagined that the flange of tube side is deformed around the imaginary axis $3 \mathrm{~h}$ and $9 \mathrm{~h}$ (see Fig. 8), due to the asymmetrical conical shape of shell, which leads to the problem of the joint tightness close to this axis. 


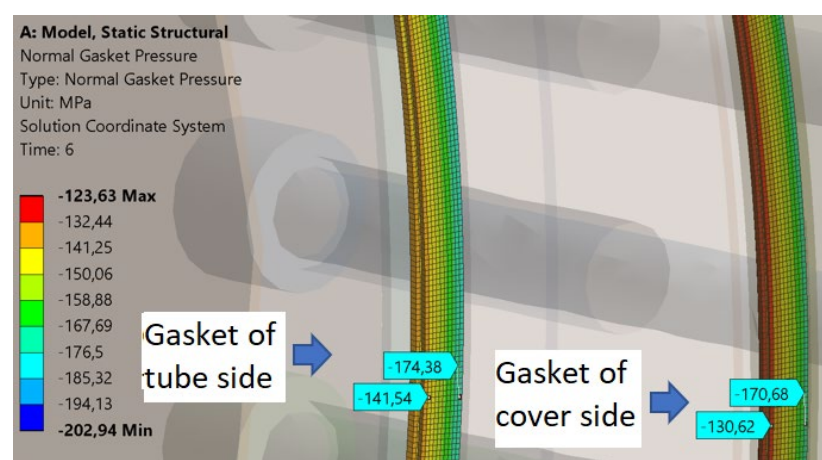

Figure 10. Normal gasket pressure in pos. $3 \mathrm{~h}$ in operating conditions

The values of normal gasket pressure for tube side flange in position $6 \mathrm{~h}$ are almost identical to values in position $12 \mathrm{~h}$. The same is true for position $3 \mathrm{~h}$ and $9 \mathrm{~h}$.

The influence of asymmetrical shell depends also character of bolt working load. The bolts in position $3 \mathrm{~h}$ and $9 \mathrm{~h}$ show a significant increase in load.

From Fig. 9 and Fig. 10 is also clear, that gasket of cover side with symmetric shall is compressed evenly in all position. That confirm again the negative influence of asymmetry shape of shell.

\section{CONCLUSION}

The results obtained in the research of influence of shape of pressure vessel shell on bolt working load and joint tightness shows the possible effect these aspects on the function of flange connections in technical practice.

From current research it is obvious, that the methodology of CSN EN 1591-1 is able to capture relatively accurately the effect of a symmetrically shaped shell connected to a flange, whether it is a cylindrical or conical connection. In this case, the use of FEM is not necessary.

The problem only occurs in case of asymmetrical shape of pressure vessel shell. Standard definitions of CSN EN 1591-1 does not provide a calculation methodology for an asymmetrical shell. Due to this reality the FEM was used. A detailed analysis proved a negative influence of asymmetrical shape of conical shell in problematic position $9 \mathrm{~h}$ and $3 \mathrm{~h}$ (see Fig. 8). This negative effect is reflected in decrease of normal gasket pressure and significant increase in bolt working load. Using FEM was designed possible solution for elimination of negative influence of the asymmetrical shape of pressure vessel shell. New design contained improvement from view of flanges stiffness. In practice, the use of a higher class of neck flanges according to the ASME Boiler and Pressure Vessel Code [ASME Code, Section VIII 2013] has proved successful. The possibility of reinforcing the conical shell at a critical area of deformation was also tested. However, it is necessary to remember that this is a nonstandard, therefore unsubstantiated modification.

The next step in the future is to verify these results by experimentally using strain gauges [Jancar 2017 et al.].

\section{ACKNOWLEDGMENTS}

The necessary material data for gaskets were supplied by company POKORNY, spol. s r. o. Trnkova 2788/115, 62800 Brno. I gratefully acknowledged this support. I also want to thank Libor Mares and Martin Tesar for their practical comments.

\section{REFERENCES}

[ASME Code, Section VIII 2013] ASME Boiler and Pressure Vessel Code, Section VIII, Rules for Construction of Pressure Vessels. Division 1. New York: ASME, July 2013.

[CSN EN 1591-1 2015] CSN EN 1591-1, Flange and their joints Design rules for gasket circular flange connections - Part 1. Praha: UNMZ, May 2015.

[CSN EN 13555 2005] CSN EN 13 555, Flanges and their joints Gasket parameters and test procedures relevant to the design rules for gasketed circular flange connections. Praha: $\mathrm{CNI}$ (Czech Standards Institute), August 2005.

[Jancar 2017 et al.] Jancar, L. and Mosler, V. and Folta, Z. Experimental Methods with Strain Gauges for Study Purposes. In: D. Herak, ed. Proceeding of the $58^{\text {th }}$ ICMD, Prague, September, 2017. Prague: Czech University Life Sciences, Dept Systems Eng, Kamycka 129, Prague 6165 21, Czech Republic, pp 124-127.ISBN 978-80-213-2769-6

[Schaaf 2003] Schaaf, M., Bartonicek, J. Calculation of Bolted Flange Connection - State of the Art (F533) [online]. August 1722, 2003, date of last revision [2003-08-17]. Available from <http://www.lib.ncsu.edu/resolver/1840.20/27149>. F06 Bolted connections and gaskets

[Zacal 2016] Zacal, J. Problem solving of Bolted Connection of a Pressure Vessel. Ostrava: VSB - Technical University of Ostrava, Department of Machine Parts and Mechanism, 2016. Available from <http://hdl.handle.net/10084/115089>.

[Zacal 2020] Zacal, J. The Methodology of Calculations of Sealed Flanged Joints of Pressure Vessels. Ostrava: VSB Technical University of Ostrava, Department of Machine Parts and Mechanism, 2020.

Available from

$<$ http://hdl.handle.net/10084/142786>.

\section{CONTACTS:}

Ing. Jiri Zacal, Ph.D.

VSB-Technical University of Ostrava, Faculty of Mechanical Engineering

Department of Machine Parts and Mechanism

17. Listopadu 15/2172, Ostrava Poruba, 708 33, Czech Republic +420 596993 288, jiri.zacal@vsb.cz, www.fs.vsb.cz

Ing. Jan Pavlik, Ph.D.

VSB-Technical University of Ostrava, Faculty of Mechanical Engineering

Department of Machine Parts and Mechanism

17. Listopadu 15/2172, Ostrava Poruba, 708 33, Czech Republic +420 596994 203, jan.pavlik@vsb.cz, www.fs.vsb.cz

Ing. Ivana Kunzova, Ph.D.

VSB-Technical University of Ostrava, Faculty of Mechanical Engineering

Department of Machine Parts and Mechanism

17. Listopadu 15/2172, Ostrava Poruba, 708 33, Czech Republic +420 596993 212, ivana.kunzova@vsb.cz, www.fs.vsb.cz 